Jurnal REKSA: Rekayasa Keuangan, Syariah, dan Audit

p-ISSN: 2089-6581 | e-ISSN: 2614-3720

Vol. 06, No. 01, 2019, pp. 73-88

\title{
EVALUASI PERHITUNGAN KOS ORGANISASI SEKTOR PUBLIK (STUDI PADA SMK BISNIS DAN TEKNOLOGI BEKASI)
}

\section{Andini Nursetiani}

Fakultas Ekonomika dan Bisnis, Universitas Gadjah Mada

Email: andininursetiani@gmail.com

\begin{abstract}
School is a place of education that belongs to the public sector organization and are not established with the sole purpose of seeking profit. Its true purpose is as an educational service and manifestation to achieve one of Indonesia's goals which is stated in the Preambule of UUD 1945, namely to educate the citizens of the nation. The aim of this research is to analyze how school determine tuition unit cost for its students, to identify unit cost for education using ABC method and to evaluate the comparison between them. This research took place at SMK Bisnis dan Teknologi Bekasi.

SMK Bisnis dan Teknologi Bekasi has three study programs such as Teknik dan Bisnis Sepeda Motor (TBSM), Bisnis Daring dan Pemasaran (BDPM) serta Perbankan dan Keuangan Mikro (PBKM). This research focused on the evaluation of unit cost measurement then compare it with $A B C$ method.

The result shows that SMK Bisnis dan Teknologi Bekasi implemented conventional method using previous year's base rate and this method caused less accurate in determining unit cost which every student need to bear. This research can be one of the recommendation on determining school unit cost for upcoming year.
\end{abstract}

Keywords: Activity, Based Costing, Cost, SPP Tariff, School.

\section{LATAR BELAKANG}

Organisasi jika dilihat dari tujuan yang dimiliki, dapat digolongkan menjadi dua yakni organisasi dengan motif mencari laba dan organisasi bermotif selain mencari laba (Halim dan Kusufi, 2012). Organisasi yang mempunyai tujuan nonprofit dikenal sebagai organisasi sektor publik. Organisasi sektor publik adalah organisasi yang mempunyai kepentingan umum dan penyediaan barang atau jasa kepada publik (Mahsun, 2013).

Secara luas organisasi sektor publik tidak hanya meliputi organisasi pemerintah. Sekolah sebagai salah satu tempat mengenyam pendidikan merupakan salah satu contoh organisasi sektor publik. Sekolah tidak didirikan dengan tujuan semata-mata untuk mencari laba melainkan sebagai pelayanan pendidikan dan wujud pencapaian salah satu tujuan negara yang tertuang dalam Pembukaan UUD 1945 yakni mencerdaskan kehidupan bangsa.

Salah satunya adalah Sekolah Menengah Kejuruan. Pendidikan menengah kejuruan adalah suatu pendidikan di jenjang menengah yang mengutamakan pengembangan kemampuan peserta didik guna melaksanakan pekerjaan dengan jenis tertentu sehingga peserta didik dapat mampu dan siap untuk memasuki lapangan kerja (Bastian, 2015). 
Andini Nursetiani | Evaluasi Perhitungan Kos Organisasi Sektor Publik ...

Selain itu sekolah harus mengurus keuangan dengan hati-hati. Sekolah dihadapkan pada tuntutan kepuasan dari masyarakat. Sekolah baik negeri maupun swasta diberikan kewenangan dalam menentukan besaran Sumbangan Pembinaan Pendidikan (SPP). Banyak cara yang dipilih sekolah dalam menentukan besaran kos atas biaya pendidikan tersebut. Namun, terkait kos ini, begitu banyak sekolah yang masih menggunakan metode konvensional dalam perhitungan. Rahmawati (2018) menyatakan bahwa penentuan kos SPP dengan metoda konvensional lebih kecil dibandingkan dengan metoda ABS.

Perhitungan kos dinilai penting dilakukan karena salah satu metode yang dapat digunakan oleh sekolah dalam menentukan kos adalah ABC. Sistem ABC merupakan suatu sistem biaya dengan mengidentifikasikan aktivitas secara individual sebagai dasar objek kos (Horgen et al, 2012). Banyak organisasi mengakui keuntungan dari penerapan sistem $\mathrm{ABC}$ lebih akurat dalam pengukuran kos produk dan membantu perusahaan menetapkan harga yang layak (Lin et al, 2016). Hal ini juga dapat diterapkan dalam pada lembaga pendidikan. Lembaga pendidikan dapat menelusuri Penerapan ABC menjadi suatu pendekatan yang memberikan fokus pada aktifitas yang dilakukan (Bastian, 2015).

Sesuai dengan perkembangan zaman, sistem akuntansi pada saat ini mulai berkembang. Namun terdapat keterbatasan sumberdaya dalam penyelenggaraan pendidikan yang membuat institusi setara sekolah harus berhati-hati dalam mengelola keuangannya. Hal ini memunculkan kebutuhan untuk mengetahui besarnya satuan kos pendidikan untuk setiap siswa dan dapat menjadi pertimbangan dalam penentuan besaran SPP di sekolah tersebut. Berdasarkan latar belakang yang sudah diuraikan, terdapat masalah yakni sekolah masih menggunakan metoda konvensional dengan pertimbangan perkiraan kemampuan masyarakat sekitar dan dasar angka tahun sebelumnya dalam menentukan besaran biaya Sumbangan Pembinaan Pendidikan (SPP) sehingga tujuan penelitian ini untuk mengidentifikasi besarnya kos dan menganalisis perbandingan perhitungan kos berdasarkan sistem konvensional dan sistem ABC yang digunakan institusi pendidikan dalam hal ini Sekolah Menengah Kejuruan. Selain itu penelitian ini berkontribusi dalam meningkatkan literasi tentang pengaruh penerapan sistem $\mathrm{ABC}$ dalam institusi pendidikan.

\section{KAJIAN LITERATUR}

\section{Akuntansi Biaya}

Michael (2004) mendefinisi biaya adalah jumlah atau pertimbangan lain yang dipertukarkan dengan properti atau layanan. Mulyadi (2015) menyatakan bahwa akuntansi biaya adalah proses, pencatatan, penggolongan, peringkasan dan penyajian, pembuatan biaya atas produk dan jasa dengan cara-cara tertentu. Mulyadi (2015) menyatakan bahwa objek akuntansi biaya adalah biaya. Biaya didefinisi kas atau nilai setara kas yang dikorbankan untuk memperoleh barang dan jasa dan diharapkan dapat membawa manfaat masa sekarang maupun masa depan bagi organisasi. Akuntansi biaya dapat digunakan sebagai dasar para pemangku kepentingan dalam membuat kebijakan. Hal ini berkaitan dengan kebijakan penentuan kos Sumbangan Pembinaan Pendidikan 
Andini Nursetiani | Evaluasi Perhitungan Kos Organisasi Sektor Publik ...

(SPP). Akuntansi biaya tidak terbatas penerapannya hanya dalam organisasi bisnis tetapi dapat diterapkan pada organisasi nonbisnis seperti sekolah.

\section{Pembiayaan dan Pendanaan Pendidikan}

Bastian (2015) menyatakan bahwa pembiayaan dalam pendidikan tidak hanya menyangkut tentang pembiayaan dalam pendidikan tetapi juga menyangkut tentang pengalokasian dana pendidikan yang tersedia. Pembiayaan pendidikan adalah upaya mengumpulkan dana pendidikan dan mengalokasikan biaya pendidikan tersebut dalam operasional dan pengembangan pendidikan dan pengembangan sumber daya manusia sehingga mampu berkerja sama dalam linkup lokal, regional, nasional maupun internasional.

Pendanaan pendidikan merupakan penyediaan sumberdaya berupa keuangan yang digunakan untuk penyelenggaraan dan pengelolaan pendidikan (Republik Indonesia, 2008). Pasal tiga Peraturan Pemerintah Nomor 48 Tahun 2008 menyatakan bahwa biaya pendidikan meliputi (a) biaya satuan pendidikan, (b) biaya penyelenggaraan dan pengelolaan pendidikan dan (c) biaya pribadi perserta didik. Pemerintah Pusat dan Pemerintah Daerah dapat berpartisipasi dalam pendanaan biaya operasional satuan pendidikan dalam bentuk hibah maupun bantuan sosial.

\section{Activity Based Cost (ABC)}

Mahal dan Hossain (2015) menyatakan bahwa sistem activity based cost (ABC) muncul sebagai suatu konsep yang telah mengubah pandangan sistem kos tradisional dan akuntansi manajemen. Horgen et al (2012) menyatakan bahwa sistem ABC merupakan suatu sistem biaya dengan mengidentifikasi aktifitas secara individual sebagai dasar objek kos. Aktivitas terdiri dari pekerjaan, event, dan unit satuan kerja dengan tujuan tertentu. Qudah dan Hroot (2017) menyatakan bahwa ABC merupakan salah satu cara yang biasa diapkai oleh perusahaan. Duh et al (2009) menyatakan bahwa masih banyak organisasi yang gagal mengimplementasikan sistem ABC.

Michael (2004) menyatakan bahwa ABC merupakan metoda akuntansi biaya dengan mengestimasi total biaya dari pelayanan termasuk biaya tenaga kerja dan material langsung juga tidak langsung dari setiap aktivitas yang mendukung. Mahal dan Hossain (2015) menyatakan bahwa sistem ABC juga dapat didefinisi sebagai alat yang kuat untuk suatu organisasi agar dapat memiliki biaya yang efektif dan efisien. Dunia dan Abdullah (2012) menyatakan bahwa seluruh biaya tidak langsung dalam sistem ABC dikumpulkan dalam beberapa kelompok biaya (cost pool) sesuai dengan aktivitas masing-masing yang terkait. Kemudian masing-masing kelompok biaya tersebut dihubungkan dengan masingmasing aktivitas dan dialokasikan berdasarkan aktivitasnya.

\section{Penelitian Terdahulu}

Penelitian terkait dengan analisis biaya dengan $\mathrm{ABC}$ sudah banyak dilakukan pada organisasi sektor bisnis, namun tidak banyak penelitian yang telah membahas mengenai 
organisasi sektor publik. Institusi pendidikan sekolah merupakan salah satu bagian dari instansi sektor publik yang bergerak bidang jasa pendidikan. Berikut beberapa penelitian terdahulu yang dapat menjadi acuan dalam penlusian.

Rachmawati (2017) mengungkapkan bahwa Standar Biaya Keluaran (SBK) yang dijadikan pendoman selama Pusdiklat Keuangan Umum Republik Indonesia belum mencakup biaya seluruhnya yang dibutuhkan oleh peserta diklat. Rachmawati (2017) menyatakan metoda $\mathrm{ABC}$ mencerminkan biaya yang digunakan oleh masing-masing diklat dalam setiap pelatihan sehingga laporan keuangan lebih akuntabel sedangkan kos yang dihitung tidak mendasarkan pada sistem ABC menghasilkan angka biaya jauh lebih rendah dan kurang akuntabel. Rahmawati (2018) mengungkapkan bahwa Sumbangan Pembinaan Pendidikan (SPP) yang ditetapkan oleh sekolah tidak menggunakan metoda khusus dan hanya menetapkan besaran Sumbangan Pembinaan Pendidikan (SPP) sesuai dengan regulasi berlaku tanpa mempertimbangkan biaya-biaya yang terjadi sehingga menghasilkan kos yang terlalu kecil.

Priyatmo (2016) mengungkapkan bahwa sistem ABC merupakan alat analisis yang memiliki prospek positif ketika diterapkan pada organisasi pemerintah. Ishter dan Hossain (2015) mengungkapkan bahwa konsep ABC terbukti berhasil diterapkan baik dalam sektor bisnis maupun sektor publik. Beberapa penelitian terdahulu yang disebut sebelumnya menjadi dasar untuk melakukan penelitian mengenai penerapan sistem ABC dalam institusi pendidikan dengan SMK Bisnis dan Teknologi Bekasi sebagai objek penelitian.

\section{METODE PENELITIAN}

\section{Pendekatan Penelitian}

Penelitian ini dibuat dengan menggunakan pendekatan deskriptif kualitatif. Tujuan dari penelitian kualitatif adalah untuk memahami perilaku dan keyankinan, mengidentifikasi proses serta memahami pengalaman orang (Hennink et al, 2011). Pendekatan ini dipilih agar dapat menganalisis dengan jelas perhitungan biaya pada SMK Bisnis dan Teknologi Bekasi agar dapat membandingkan antara metode konvensional yang digunakan dengan metode $\mathrm{ABC}$.

\section{Subjek Penelitian}

Penelitian ini dilakukan di salah satu sekolah menengah kejuruan swasta di Kota Bekasi yakni SMK Bisnis dan Teknologi Bekasi. Dalam hal ini, penelitian memfokuskan pada penentuan biaya satuan pendidikan tiap siswa serta melakukan analisis untuk membandingkan metode yang digunakan oleh sekolah dengan menggunakan metode ABC. Tahun anggaran yang digunakan dalam penelitian ini adalah TA 2017/2018.

\section{Sumber Data}

Penelitian ini menggunakan data sekunder serta data primer. Data sekunder pada penelitian ini meliputi sumber pustaka yang tersedia serta data fisik yang ada di SMK 
Bisnis dan Teknologi Bekasi. Data primer pada penelitian ini adalah wawancara langsung dengan pihak sekolah. Terdapat 5 responden yang akan menjadi narasumber dalam penelitian ini. Responden seluruhnya merupakan orang yang memiliki hubungan di SMK Bisnis dan Teknologi Bekasi.

Tabel 3.1. Responden Penelitian

\begin{tabular}{cll}
\hline No. & \multicolumn{1}{c}{ Nama Responden } & \multicolumn{1}{c}{ Jabatan } \\
\hline 1. & Agus Setia Budi, M.MPd. & Kepala Sekolah \\
2. & Kris Budiyani, S.Pd. & Ketua Yayasan \\
3. & Tukiyo & Ketua Komite Sekolah \\
4. & Yamini, SE & Bendahara Sekolah \\
5. & Nani Supartini & Tata Usaha \\
\hline
\end{tabular}

Sumber: Data diolah, 2018.

\section{Teknik Analisis Data}

Teknik analisis data yang digunakan bersifat kualitatif. Hal ini sesuai dengan tujuan penelitian yakni mengevaluasi perhitungan biaya satuan unit pendidikan dan membandingkan dengan metode $\mathrm{ABC}$. Tahapan yang dilakukan sesuai dengan implementasi sistem $\mathrm{ABC}$ sebagai berikut.

1. Identifikasi aktivitas serta atribut

2. Mengalokasikan kos pada tiap aktivitas

3. Mengalokasikan kos pada produk/jasa

Selanjutnya dapat dilakukan analisis perbandingan antara metode konvensional yang digunakan oleh SMK Bisnis dan Teknologi dengan hasil analisis data dengan metode ABC. Setelah analisis dan evaluasi dilakukan, kemudian akan menghasilkan suatu evaluasi yang dapat menjadi rekomendasi untuk sekolah sebagai pertimbangan dalam membuat kebijakan terkait penentuan SPP sekolah.

\section{HASIL DAN PEMBAHASAN}

\section{Perancangan Model Activty Based Cost}

Perencanaan model ABC dilakukan dengan beberapa tahap. Tahap pertama yakni mementukan atau mengidentifikasi aktivitas kemudian mengelompokan aktivitas tersebut ke dalam kelompok yang sama. Selanjutya menentukan tarif tiap unit kemudian dilakukan permodelan $\mathrm{ABC}$. Terakhir, setelah dibuat perhitungan $\mathrm{ABC}$ kemudian dibuatlah rincian hasil hitung untuk tiap siswa per paket keahlian. Dalam hal ini organisasi sektor 
publik khususnya sekolah tidak memiliki tujuan utama dalam mencari laba maka dapat menggunakan asumsi Break Even Point. Sehingga kos setiap siswa setiap jurusan per bulannya merupakan tarif SPP.

Tahap pertama yang dilakukan yakni melakukan identifikasi terhadap aktivitasaktivitas yang terjadi di SMK Bisnis dan Teknologi Bekasi di Tahun Ajaran 2017/2018. Berikut ini merupakan bagan alur kegiatan siswa SMK Bisnis dan Teknologi Bekasi.

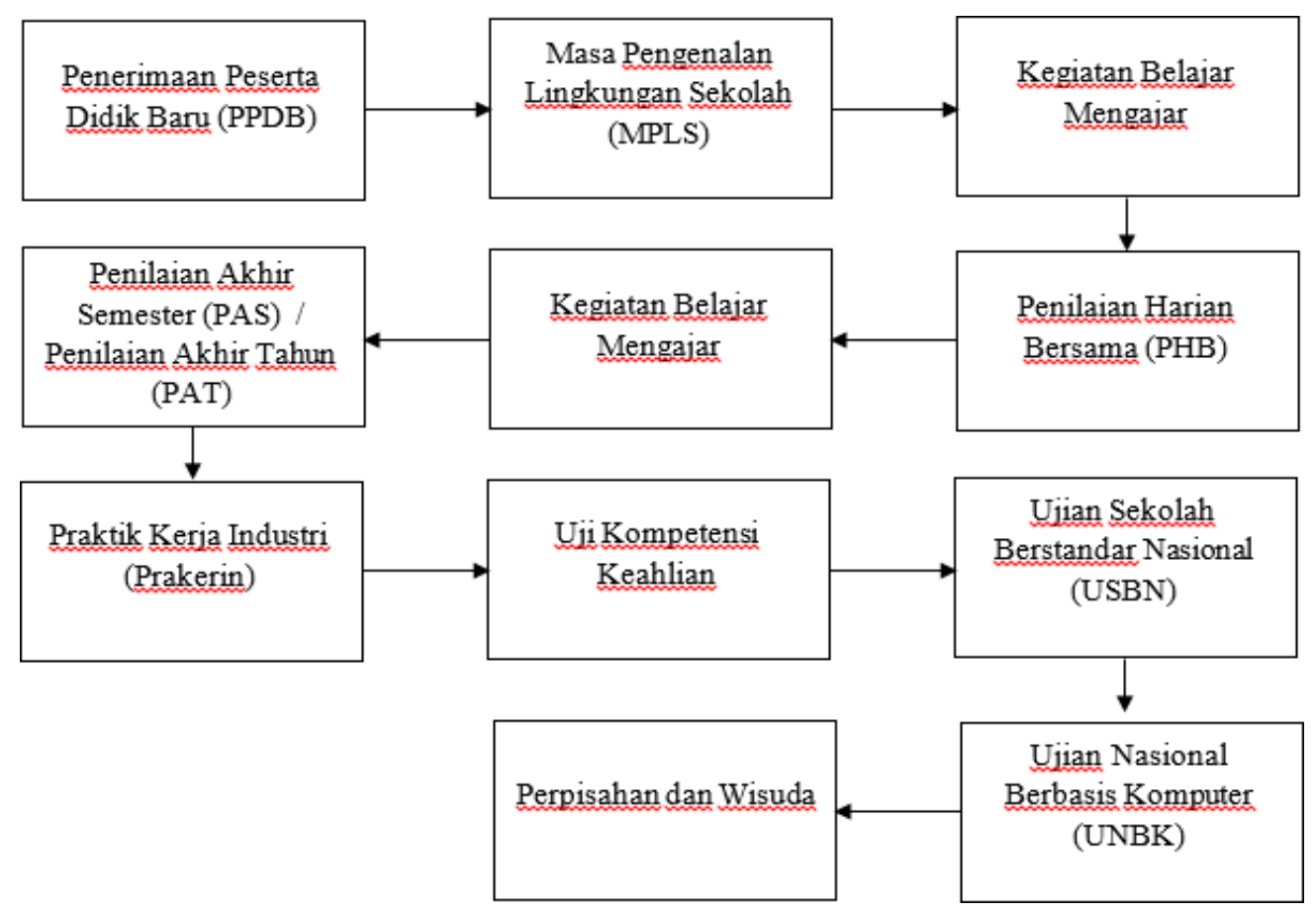

Gambar 4.1. Alur Aktivitas Tahun Ajaran 2017/2018

Sumber: Data Diolah, 2019

Tiap aktivitas yang telah ditentukan pada tahap sebelumnya akan dikelompokan kedalam level berikut ini.

1. Level Unit

Aktivitas pada level ini merupakan aktivitas yang dilakukan oleh setiap unit siswa. Biaya pada level ini bersifat proporsional dengan jumlah unit siswa yang bersekolah.

2. Level Batch

Aktivitas pada level batch merupakan aktivitas yang dilakukan untuk sekelompok siswa. Besaran biaya aktivitas pada level ini dipengaruhi oleh jumlah kelompok siswa yang menjalankan aktivitas tertentu.

3. Level Fasilitas

Aktivitas untuk level fasilitas yaitu aktivitas-aktivitas yang mendukung kegiatan operasional sekolah yang tidak dipengaruhi oleh berapapun jumlah siswa yang bersekolah. 
Andini Nursetiani | Evaluasi Perhitungan Kos Organisasi Sektor Publik ...

Tabel 4.1. Penentuan Level Tiap Aktivitas

\begin{tabular}{|c|c|c|}
\hline No & Aktivitas & Level Aktivitas \\
\hline 1 & Penerimaan Peserta Didik Baru & Batch \\
\hline 2 & Masa Pengenalan Lingkungan Sekolah & Batch \\
\hline \multirow[t]{11}{*}{3} & Kegiatan Belajar Mengajar & \\
\hline & 3.1 Pengadaan Sarana Penunjang KBM & Unit \\
\hline & 3.2 Pengadaan Buku Teks Pelajaran & Unit \\
\hline & 3.3 Penilaian Harian Bersama (PHB) & Unit \\
\hline & 3.4 Penilaian Akhir Semester (PAS) & Unit \\
\hline & 3.5 Penilaian Akhir Tahun (PAT) & Unit \\
\hline & 3.6 Remedial dan Pengayaan & Unit \\
\hline & 3.7 Pendalaman Materi & Batch \\
\hline & 3.8 Uji Kompetensi & Batch \\
\hline & 3.9 Ujian Sekolah Berstandar Nasional (USBN) & Batch \\
\hline & 3.10 Ujian Nasional Berbasis Komputer (UNBK) & Batch \\
\hline \multirow[t]{10}{*}{4} & Penggajian (Honor Pendidik dan Tenaga Kependidikan) & \\
\hline & 4.1 Honor Guru Pengajar & Batch \\
\hline & 4.2 Honor Tenaga Kependidikan Paket Keahlian & Batch \\
\hline & 4.3 Wali Kelas & Batch \\
\hline & 4.4 Piket & Fasilitas \\
\hline & 4.5 Honor Tenaga Kependidikan Umum & Fasilitas \\
\hline & 4.6 Honor Pimpinan dan Struktural & Fasilitas \\
\hline & 4.7 Kebersihan dan Keamanan & Fasilitas \\
\hline & 4.8 Tunjangan Hari Raya & Fasilitas \\
\hline & 4.9 Tunjangan Jabatan & Fasilitas \\
\hline \multirow[t]{6}{*}{5} & Kegiatan Kesiswaan & \\
\hline & 5.1 Ekstrakulikuler & Batch \\
\hline & 5.2 LDKS & Batch \\
\hline & 5.3 Pentas Seni & Fasilitas \\
\hline & 5.4 HUT RI & Fasilitas \\
\hline & 5.5 Peringatan Hari Besar Agama & Fasilitas \\
\hline 6 & Pengadaan dan Pemeliharaan Sarana \& Prasarana & \\
\hline
\end{tabular}

Sumber: Data Diolah, 2019.

Aktivitas secara rinci telah diklasifikasi sesuai dengan level masing masing. Biaya untuk setiap kelompok kemudian dijumlahkan sehingga dihasilkan total biaya untuk setiap kelompok. Tarif per unit dihitung dengan cara membagi jumlah total biaya kepada masing-masing aktivitas dengan jumlah cost driver. Setelah tarif biaya per unit diketahui, selanjutnya adalah membebankan biaya pada siswa tiap program keahlian. 
Andini Nursetiani | Evaluasi Perhitungan Kos Organisasi Sektor Publik ...

\section{Pembentukan Model Activity Based Cost}

Perhitungan model ABC untuk setiap paket keahlian akan dilakukan setelah mengetahui seluruh tarif di tiap aktivitas. Paket keahlian di SMK Bisnis dan Teknologi terdiri atas Keahlian Teknik dan Bisnis Sepeda Motor (TBSM), Bisnis Daring dan Pemasaran (BDPM) dan Perbankan dan Keuangan Mikro (PBKM). Hasil perhitungan tiap paket keahlian dapat dilihat dalam bagian lampiran penelitian.

\section{Perhitungan dengan Model Activity Based Cost}

Berikut ini merupakan hasil hitung yang telah dilakukan dengan metode $\mathrm{ABC}$ untuk setiap paket keahlian.

Tabel 4.2. Perbandingan Hasil Perhitungan Model ABC dengan SPP

\begin{tabular}{clrr}
\hline No & Paket Keahlian & $\begin{array}{c}\text { Kos menurut } \\
\text { Metode ABC }\end{array}$ & SPP yang Berlaku \\
\hline 1 & Teknik dan Bisnis Sepeda Motor (TBSM) & 300.516 & 175.000 \\
2 & Bisnis Daring dan Pemasaran (BDPM) & 291.287 & 175.000 \\
3 & Perbankan dan Keuangan Mikro (PBKM) & 275.980 & 175.000 \\
\hline
\end{tabular}

Sumber: Data Diolah, 2019

Hasil perhitungan di atas menunjukkan tarif SPP yang berlaku pada saat ini dinilai lebih rendah dibandingkan dengan perhitungan dengan metode ABC. Perhitungan dengan Metode ABC tidak termasuk dengan uang pangkal dan bantuan dari pemerintah maupun pihak luar. Hal ini karena uang pangkal dikhususkan untuk membangun fasilitas di SMK Bisnis dan Teknologi sehingga tidak diikutsertakan dalam perhitungan dalam Metode ABC. Perhitungan dengan sudut pandang metode $A B C$ dapat digunakan sebagai evaluasi terhadap penentuan SPP yang berlaku untuk kedepannya. Hal ini bertujuan agar sekolah dapat membuat informasi keuangan dan membuat keputusan yang lebih akurat dalam merancang RKAS dan RAPBS tahun selanjutnya.

Nilai kos yang lebih tinggi dari tariff SPP di SMK Bisnis dan Teknologi Bekasi memang untuk saat ini masih dapat ditutupi dengan bantuan yang didapat dari pemerintah. Namun jika terus dibiarkan dapat menyebabkan sekolah akan bergantung pada sumbangan pemerintah maupun pihak lain. Jika di kemudian hari terdapat perubahan kebijakan dari pemerintah yang kurang menguntungkan sekolah, hal tersebut akan memberikan masalah untuk sekolah itu sendiri

\section{SIMPULAN}

1. Belum adanya perhitungan secara matematis dalam menentukan tarif SPP yang dibebankan kepada setiap siswanya. Penentuan besaran biaya pendidikan didasari pada pertimbangan dasar angka tahun sebelumnya serta pertimbangan perkiraan kemampuan masyarakat sekitar. 
Andini Nursetiani | Evaluasi Perhitungan Kos Organisasi Sektor Publik ...

2. Metode $A B C$ dapat menjadi salah satu alternatif yang dapat dilakukan dalam menentukan tarif SPP di SMK Bisnis dan Teknologi Bekasi. Organisasi publik tidak memiliki tujuan utama dalam mencari laba maka dapat menggunakan asumsi Break Even Point. Sehingga kos setiap siswa setiap jurusan per bulannya merupakan tarif SPP.

3. Hasil perhitungan yang dilakukan dengan metode ABC, nilai kos untuk setiap siswa perbulannya berbeda pada tiap paket keahlian. Tarif SPP yang berlaku pada saat ini dinilai terlalu rendah dibandingkan perhitungan dengan metode $\mathrm{ABC}$.

\section{SARAN}

1. Perlu adanya perhitungan yang lebih akurat dalam menentukan tarif SPP, hal ini ditujukan agar sekolah lebih fleksibel dalam menghadapi tantangan yang berganti di setiap tahunnya. ABC dapat menjadi salah satu metode alternatif yang dapat memberikan gambaran yang lebih akurat dibandingkan metode tradisional. Akademisi dapat dilibatkan dalam membantu perhitungan biaya.

\section{DAFTAR PUSTAKA}

Al-Qudah, Laith Akram Muflih dan Yusuf Ali Khalaf Al-Hroot. 2017. The Implementation Activity-based Costing Technique and Its Impact on Profitability: A Study of Listed Manufacturing Companies in Jordan. International Journal of Economics and Financial Issues 7(2): 271-276.

Bastian, Indra. 2015. Akuntansi Pendidikan Pengelolaan Organisasi Pendidikan Edisi Kedua. Yogyakarta: BPFE.

Boland, Tony dan alan Fowler. 2000. A Systems Perspective of Performance in Public Sector Organisations. The International Journal of Public Sector Management 13(5): 417-446.

Boyne, George A. 2002. Public and Private Management: What's the Difference?

Journal of Management Studies 39(1): 97-122.

Cokins, Gari dan Sorinel Capusneanu. 2010. Cost Drivers, Evolution and Benefits. Theoretical and Applied Economics Volume XVII 8(549): 7-16.

Duh, Rong-Ruey dkk. 2009. The Design and Implementation of Activity-Based Costing: A Case Study of a Taiwanese Textile Company. International Journal of Accounting and Information Management 17(1):27-52.

Dunia, Firdaus Ahmad dan Wasilah Abdullah. 2012. Akuntansi Biaya Edisi 3.Jakarta: Salemba Empat.

Halim, Abdul dan Syam Kusufi. 2012. Teori, Konsep, dan Aplikasi Akuntansi Sektor Publik. Jakarta: Salemba Empat.

Hennink, Monique, Inge Hutter, dan Ajay Bailey. 2011. Qualitative Research Method. 1st ed. Sage Publications. Management Control System.

Horgren, Charles T., Srikant M. Datar, Madhav Rajan. 2012. Cost Accounting $14^{\text {th }}$ Edition. New Jersey: Pearson. 
Andini Nursetiani | Evaluasi Perhitungan Kos Organisasi Sektor Publik ...

Lin, Huijuan, Yanglin Li dan Wanxin Li. 2016. An Empirical Analysis of Activity Based Costing in Chinese Entterprise. Journal of Finance and Accountig 4(5): 301-309.

Mahal, Ishter dan Akram Hossain. 2015. Activity-Based Costing (ABC) - An Effective Tool for Better Management. Research Journal of Finance 6(4): 66-73.

Mahsun, Moh., Firma Sulstyowati., dan Heribertus A. Purwanugraha. 2013. Akuntansi Sektor Publik. Yogyakarta: BPFE.

Mahsun, Mohamad. 2013. Pengukuran Kinerja Sektor Publik. Yogyakarta: BPFE. Mardiasmo. 2009. Akuntansi Sektor Publik. Yogyakarta: Penerbit Andi.

Moleong, Lexy. 2014. Metodologi Penelitian Kualitatif. Revisi. Bandung: Remaja

Michel, R. Gregory. 2004. Cost Analysis and Activity-Based Costing for Government.USA: The Government Finance Officers Association (GFOA) of The United States and Canada

Mulyadi. 2007. ACTIVTY-BASED COST SYSTEM. Yogyakarta: UPP STIM YKPN.

Mulyadi. 2015. Akuntansi Biaya Edisi Ke-5. Yogyakarta: UPP STIM YKPN.

Pemerintah Daerah Provinsi Jawa Barat. 2017. Pedoman Bantuan Pendidikan Menengah Universal (BPMU) Provinsi Jawa Barat. Bandung.

Rachmawati, Desiana. 2017. Analisis Perhitungan Kos Berbasis Aktivitas (Studi pada Pusdiklat Keuangan Umum Kemenkeu RI) Thesis Akuntansi UGM.

Raiborn, Cecily A. dan Michael R. Kinney. 2011.Akuntansi Biaya: Dasar dan Perkembangan Edisi 7. Jakarta: Penerbit Salemba Empat.

Republik Indonesia. 2008. Peraturan Pemerintah No. 48 Tahun 2008 tentang Pendanaan Pendidikan. Jakarta.

Republik Indonesia. 2018. Peraturan Menteri Pendidikan dan Kebudayaan No. 1 Tahun 2018 tentang Petunjuk Teknis Bantuan Operasional Sekolah. Jakarta. 
Andini Nursetiani | Evaluasi Perhitungan Kos Organisasi Sektor Publik ...

\section{LAMPIRAN}

Perhitungan Kos Paket Keahlian Teknik dan Bisnis Sepeda Motor (TBSM)

\begin{tabular}{lll}
\hline No & Aktivitas & Jumlah \\
\hline 1 & Aktivitas Berlevel Unit &
\end{tabular}

A 3 Aktivitas KBM

2.380 .630

$\begin{array}{llr}3.1 & \text { Pengadaan Sarana Penunjang KBM } & 902.212 \\ 3.2 & \text { Pengadaan Buku Teks Pelajaran } & 538.357 \\ 3.3 & \text { PHB } & 430.755 \\ 3.4 & \text { PAS } & 277.308 \\ 3.5 & \text { PAT } & 180.958 \\ 3.6 & \text { Remedial dan Pengayaan } & 51.040\end{array}$

2 Aktivitas Berlevel Batch
A 2 MPLS
94.209
B 3 Aktivitas KBM
688.487
3.7 Pendalaman Materi
286.573
3.8 Uji Kompetensi
270.854
3.9 USBN
92.496
3.10 UNBK
38.564
C 4 Penggajian
1.192 .150
4.1 Honor Guru Pengajar
838.879
4.2 Honor Tenaga Kependidikan Paket Keahlian
252.336
4.3 Wali Kelas
100.935
D 5 Kegiatan Kesiswaan
930.211
5.1 Ekstrakulikuler
518.573
5.2 LDKS
411.638
9 Bursa Kerja Khusus (BKK)
577.803
E 9.1 Praktek Kerja Industri
462.121
9.2 Kunjungan Industri
115.682
F 10 Pelepasan dan Wisuda
435.363
10.1 Perpisahan Kelas XII
435.363
10.2 Wisuda 
3 Aktivitas Berlevel Fasilitas

A 1 Penerimaan Siswa Baru

B 4 Penggajian

4.4 Piket

61.248

4.5 Honor Tenaga Kependidikan Umum

68.053

4.6 Honor Pimpinan dan Struktural

731.569

4.7 Kebersihan dan Keamanan

316.446

4.8 Tunjangan Hari Raya

144.612

4.9 Tunjangan Jabatan

1.122 .873

C 5 Kegiatan Kesiswaan

423.822

5.3 Pentas Seni

52.174

5.4 HUT RI

5.5 Peringatan Hari Besar Agama

341.847

D 6 Pengadaan dan Pemeliharaan Sarana \& Prasarana

6.1 Belanja Peralatan Pendidikan

138.941

6.2 Pemeliharaan dan Perbaikan Ringan Sarpras Sekolah

311.909

6.3 Pemasangan Instalasi dan Penambahan Daya Listrik

11.342

34.026

6.4 Pengembangan Perpustakaan

496.219

E 7 Manajemen dan Pengembangan Sekolah

758.416

7.1 Lokakarya dan Pengembangan KTSP

180.788

7.2 Pengembangan Standar Pengelolaan

410.331

7.3 Pembinaan Profesi Guru

167.297

F 8 Penggunaan Layanan dan Jasa

226.560

8.1 Langganan Listrik

182.042

8.2 Langganan Telpon

7.089

8.3 Langganan Internet

32.892

8.4 Langganan Koran dan Lainnya

4.537

G 11 Kegiatan Lain Penunjang Aktivitas Sekolah

11.1 Kegiatan Rumah Tangga Sekolah

90.510

90.510

11.2 Lain-lain 
Andini Nursetiani | Evaluasi Perhitungan Kos Organisasi Sektor Publik ...

Perhitungan Kos Paket Keahlian Bisnis Daring dan Pemasaran

\begin{tabular}{|c|c|c|c|c|}
\hline No & & Aktivitas & \multicolumn{2}{|c|}{ Jumlah } \\
\hline \multicolumn{5}{|c|}{ Aktivitas Berlevel Unit } \\
\hline & A & 3 Aktivitas KBM & & 2.380 .630 \\
\hline & & 3.1Pengadaan Sarana Penunjang KBM & 902.212 & \\
\hline & & 3.2Pengadaan Buku Teks Pelajaran & 538.357 & \\
\hline & & 3.3РНВ & 430.755 & \\
\hline & & 3.4PAS & 277.308 & \\
\hline & & 3.5PAT & 180.958 & \\
\hline & & 3.6Remedial dan Pengayaan & 51.040 & \\
\hline \multirow[t]{20}{*}{2} & \multicolumn{4}{|c|}{ Aktivitas Berlevel Batch } \\
\hline & A & 2 MPLS & & 94.209 \\
\hline & $\mathrm{B}$ & 3 Aktivitas KBM & & 688.487 \\
\hline & & 3.7Pendalaman Materi & 286.573 & \\
\hline & & 3.8Uji Kompetensi & 270.854 & \\
\hline & & 3.9USBN & 92.496. & \\
\hline & & 3.10UNBK & 38.564 & \\
\hline & $\mathrm{C}$ & 4 Penggajian & & 982.500 \\
\hline & & 4.1Honor Guru Pengajar & 810.441 & \\
\hline & & 4.2Honor Tenaga Kependidikan Paket Keahlian & 66.176 & \\
\hline & & 4.3Wali Kelas & 105.882 & \\
\hline & $\mathrm{D}$ & 5 Kegiatan Kesiswaan & & 930.211 \\
\hline & & 5.1Ekstrakulikuler & 518.573 & \\
\hline & & 5.2LDKS & 411.638 & \\
\hline & $\mathrm{E}$ & 9 Bursa Kerja Khusus (BKK) & & 455.224 \\
\hline & & 9.1Praktek Kerja Industri & 455.224 & \\
\hline & & 9.2Kunjungan Industri & - & \\
\hline & F 10 & Pelepasan dan Wisuda & & 435.363 \\
\hline & & 10.1Perpisahan Kelas XII & 435.363 & \\
\hline & & 10.2Wisuda & - & \\
\hline
\end{tabular}


3 Aktivitas Berlevel Fasilitas

A 1 Penerimaan Siswa Baru

79.395

B 4 Penggajian

2.444 .802

4.4Piket

61.248

4.5Honor Tenaga Kependidikan Umum

68.053

4.6Honor Pimpinan dan Struktural

731.569

4.7Kebersihan dan Keamanan

316.446

4.8Tunjangan Hari Raya

144.612

4.9Tunjangan Jabatan

1.122 .873

C 5 Kegiatan Kesiswaan

423.822

5.3Pentas Seni

52.174

5.4HUT RI

29.802

5.5Peringatan Hari Besar Agama

D 6 Pengadaan dan Pemeliharaan Sarana \& Prasarana

6.1Belanja Peralatan Pendidikan

6.2Pemeliharaan dan Perbaikan Ringan Sarpras

311.909 Sekolah

6.3Pemasangan Instalasi dan Penambahan Daya Listrik

6.4Pengembangan Perpustakaan

11.342

34.026

E 7 Manajemen dan Pengembangan Sekolah

758.416

7.1Lokakarya dan Pengembangan KTSP

180.788

7.2Pengembangan Standar Pengelolaan

410.331

7.3Pembinaan Profesi Guru

167.297

F 8 Penggunaan Layanan dan Jasa

226.560

8.1Langganan Listrik

182.042

8.2Langganan Telpon

7.089

8.3Langganan Internet

32.892

8.4Langganan Koran dan Lainnya

4.537

G 11 Kegiatan Lain Penunjang Aktivitas Sekolah

90.510

11.1Kegiatan Rumah Tangga Sekolah

90.510

11.2Lain-lain

Total

10.486 .349

SPP Per Bulan

291.287 
Andini Nursetiani | Evaluasi Perhitungan Kos Organisasi Sektor Publik ...

Perhitungan Kos Paket Keahlian Perbankan dan Keuangan Mikro

\begin{tabular}{ccc}
\hline No & Aktivitas & Jumlah \\
\hline 1 & Aktivitas Berlevel Unit &
\end{tabular}

A 3 Aktivitas KBM

2.380 .630

3.1Pengadaan Sarana Penunjang KBM

902.212

3.2Pengadaan Buku Teks Pelajaran

538.357

3.3РHB

430.755

3.4PAS

277.308

3.5PAT

180.958

3.6Remedial dan Pengayaan

51.040

2 Aktivitas Berlevel Batch
A 2 MPLS
94.209
B 3 Aktivitas KBM
270.854
3.7Pendalaman Materi
286.573
3.8Uji Kompetensi
270.854
3.9USBN
92.496
3.10UNBK
38.564
C 4 Penggajian
886.642
4.1Honor Guru Pengajar
736.744
4.2Honor Tenaga Kependidikan Paket Keahlian
66.176
4.3Wali Kelas
83.721
D 5 Kegiatan Kesiswaan
930.211
E $\quad$ 5.1Ekstrakulikuler
518.573
5.2LDKS
411.638
9 Bursa Kerja Khusus (BKK)
9.1 Praktek Kerja Industri
9.2 Kunjungan Industri
10 Pelepasan dan Wisuda
435.363
10.1 Perpisahan Kelas XII
435.363
10.2 Wisuda 
Andini Nursetiani | Evaluasi Perhitungan Kos Organisasi Sektor Publik ...

3 Aktivitas Berlevel Fasilitas

A 1 Penerimaan Siswa Baru

79.395

B 4 Penggajian

2.444 .802

4.4Piket

61.248

4.5Honor Tenaga Kependidikan Umum

68.053

4.6Honor Pimpinan dan Struktural

731.569

4.7Kebersihan dan Keamanan

316.446

4.8Tunjangan Hari Raya

144.612

4.9Tunjangan Jabatan

1.122 .873

C 5 Kegiatan Kesiswaan

423.822

5.3Pentas Seni

52.174

5.4HUT RI

29.802

5.5Peringatan Hari Besar Agama

341.847

D 6 Pengadaan dan Pemeliharaan Sarana \& Prasarana

6.1Belanja Peralatan Pendidikan

138.941

6.2Pemeliharaan dan Perbaikan Ringan Sarpras Sekolah

311.909

6.3Pemasangan Instalasi dan Penambahan Daya Listrik

6.4Pengembangan Perpustakaan

34.026

E 7 Manajemen dan Pengembangan Sekolah

758.416

7.1Lokakarya dan Pengembangan KTSP

180.788

7.2Pengembangan Standar Pengelolaan

410.331

7.3Pembinaan Profesi Guru

167.297

F 8 Penggunaan Layanan dan Jasa

226.560

8.1Langganan Listrik

182.042

8.2Langganan Telpon

8.3Langganan Internet

8.4Langganan Koran dan Lainnya

G 11 Kegiatan Lain Penunjang Aktivitas Sekolah

90.510

11.1Kegiatan Rumah Tangga Sekolah

90.510

11.2Lain-lain

Total 9.935 .266

SPP Per Bulan 275.980 